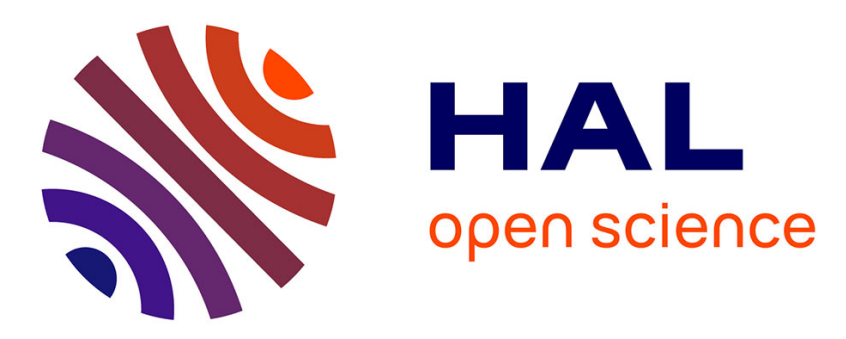

\title{
Investigation of ion transport in chemically tuned pillared graphene materials through electrochemical impedance analysis
}

Harish Banda, Sandy Périé, Barbara Daffos, Lionel Dubois, Olivier Crosnier, Patrice Simon, Pierre-Louis Taberna, Florence Duclairoir

\section{To cite this version:}

Harish Banda, Sandy Périé, Barbara Daffos, Lionel Dubois, Olivier Crosnier, et al.. Investigation of ion transport in chemically tuned pillared graphene materials through electrochemical impedance analysis. Electrochimica Acta, 2019, 296, pp.882-890. 10.1016/j.electacta.2018.11.122 . hal-02001020

\author{
HAL Id: hal-02001020 \\ https://hal.science/hal-02001020
}

Submitted on 21 May 2019

HAL is a multi-disciplinary open access archive for the deposit and dissemination of scientific research documents, whether they are published or not. The documents may come from teaching and research institutions in France or abroad, or from public or private research centers.
L'archive ouverte pluridisciplinaire HAL, est destinée au dépôt et à la diffusion de documents scientifiques de niveau recherche, publiés ou non, émanant des établissements d'enseignement et de recherche français ou étrangers, des laboratoires publics ou privés. 


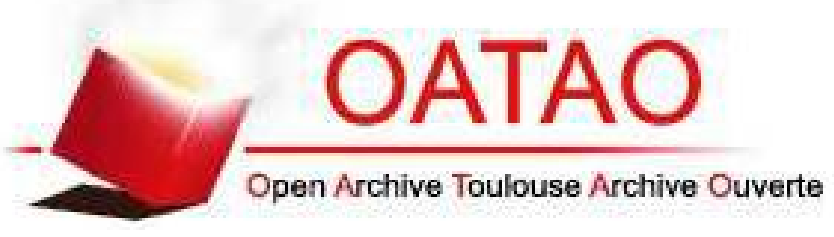

\section{Open Archive Toulouse Archive Ouverte (OATAO)}

OATAO is an open access repository that collects the work of some Toulouse researchers and makes it freely available over the web where possible.

This is an author's version published in: http://oatao.univ-toulouse.fr/21778

Official URL: https://doi.org/10.1016/j.electacta.2018.11.122

\section{To cite this version:}

Banda, Harish and Périé, Sandy and Daffos, Barbara and Dubois, Lionel and Crosnier, Olivier and Simon, Patrice and Taberna, Pierre-Louis and Duclairoir, Florence Investigation of ion transport in chemically tuned pillared graphene materials through electrochemical impedance analysis. (2019) Electrochimica Acta, 296. 882-890. ISSN 0013-4686

Any correspondence concerning this service should be sent to the repository administrator: tech-oatao@listes-diff.inp-toulouse.fr 


\title{
Investigation of ion transport in chemically tuned pillared graphene materials through electrochemical impedance analysis
}

\author{
Harish Banda a, Sandy Périé ${ }^{a}$, Barbara Daffos ${ }^{\text {d, b }}{ }^{\text {, Lionel Dubois }}{ }^{a}$, Olivier Crosnier ${ }^{\text {d, c }}$,

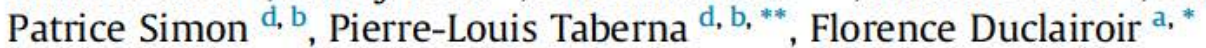 \\ a Univ. Grenoble Alpes, CEA, CNRS, INAC, SyMMES, Grenoble, 38000, France \\ b CIRIMAT, Université Toulouse, CNRS, INPT, UPS, 31062, Toulouse, France \\ ' Institut des matériaux Jean Rouxel (IMN), Université Nantes, CNRS, Nantes, 44300, France \\ ' Réseau sur le Stockage Electrochimique de IEnergie (RS2E), FR CNRS, 3459, France
}

Keywords:

Graphene

Grafting

Ion transport

Electrochemical impedance

Spectroscopy

\begin{abstract}
A B S T R A C T
Chemically tuned pillared graphene structures show ability to limit restacking of graphene sheets for electrochemical energy storage in SCs. A comprehensive electrochemical characterization using various ion sizes allowed identification of ion sieving in the cross linked galleries of reduced pillared graphene materials (RPs). The access to the cross linked galleries, which provide additional ion sorption sites, offered slightly increased capacitances in RPs compared to completely restacked sheets in reduced graphene oxide (RGO). We performed electrochemical impedance analyses on RPs and RGO to under stand the ion transport inside the cross linked graphene galleries. RGO adsorbs ions in the inter particle micro/meso pores and the ion access to such sites from the bulk electrolyte occurs with relative ease. RPs sieve ions into their inter layer gallery pores based on effective ion sizes and the ion transport process is resistive compared to RGO. A control study using 3D pillared graphene hydrogel with improved macro porosity assigns this resistive behavior and the moderate capacitances to limited ion access to the active sites due to excess number of pillars. The obtained results on the ion transport dynamics between graphene layers provide perspectives towards further optimization of these graphene materials for SCS.
\end{abstract}

\section{Introduction}

Supercapacitors (SCs) or electrochemical double layer capaci tors are electrochemical energy storage devices able to deliver high power densities with excellent cycle life $[1,2]$. These characteristics are made possible by the charge storage process involving a charge separation at the electrode electrolyte interface via fast adsorption of electrolytic ions at the electrode surface. However, these systems are also characterized by limited energy densities and thus are widely studied as complementary to batteries [3]. To improve the energy densities, researchers are working on new systems with porous carbons, or the development of pseudocapacitive materials with additional faradaic processes, or hybrid systems that operate

\footnotetext{
* Corresponding author.

** Corresponding author. CIRIMAT, Universite Toulouse, CNRS, INPT, UPS, 31062 , Toulouse, France.

E-mail addresses: taberna@chimie.ups-tlse.fr (P.-L. Taberna), florence,duclairor@ cea.fr (F. Duclairoir).
}

between batteries and SCs [4-6].

Among various carbons, activated carbons (ACs) have been widely studied for SCs applications owing to their high specific surface areas (SSA) and low material costs [4]. Interest in ACs also lies in their tunable porous structures that allowed analysis of the impact of pore sizes on specific capacitances $[7,8]$. These studies revealed that in addition to high surface areas, matching pore sizes to electrolytic ion sizes also enable high capacitances [9-11]. Extensive analyses on ion sieving in these pores have discovered that the high capacitances are a result of a partial desolvation and confinement of ions in these pores [12-14]. Among other carbon derivatives tested, graphene has been studied as an electrode ma terial candidate [15-17]. The derived research paths have mainly focused on tuning graphene sample porosity [18,19], for example, by creating holes inside the graphene sheets, or by forming gra phene aerogels displaying porosities adapted for efficient electro lyte ion transfer $[20,21]$. In parallel, many research paths involve the use of graphene as a support for a faradaic or non faradaic component to improve the overall capacity of the system $[22,23]$. 
Recently, our group proposed pillared graphene structures with organic molecules as pillars to prevent the significant restacking of graphene sheets during chemical reduction. We predict that such pillared structures would offer higher specific capacitances with more electrochemical active sites available for ion sorption. Hence, an interesting class of materials with varied inter graphene layer separation (d spacing), named as reduced pillared materials (RPs), were readily synthesized by varying the size of the pillar (alkyldi amine with 5, 6, 8 Cs) used [24-26]. In the course of related elec trochemical studies, ion sieving behavior was observed in these graphene derived materials [24]. A clear dependency between $\mathrm{d}$ spacing of the inter layer galleries and electrolytic ion sizes was noted: ions with sizes smaller than d spacing can access gallery pores whereas larger ions cannot access the surface area inside the galleries [24]. The cross linked galleries in these materials sieve ions based on their size and hence demonstrate a potential for enhanced capacitances through optimization of $\mathrm{d}$ spacing/ion size couple [27]. While this phenomenon has been clearly identified and explained using cyclic voltammetry (CV) experiments, additional electrochemical impedance spectroscopy (EIS) studies are pre sented in this paper with further insights on the electrolytic ion transport in between the graphene layers. This analysis of ion dy namics inside the graphene galleries gives new perspectives and is of direct interest towards optimizing graphene materials for SCs. So, herein, pillared graphene materials with a d spacing of 0.78 and $0.80 \mathrm{~nm}$ obtained with pillars of 1,5 diaminopentane and 1,6 diaminohexane respectively - were tested in various tetraalky lammonium tetrafluoroborate salt solutions in acetonitrile. Impedance analyses were performed under positive and negative polarizations to obtain the distinct anion and cation responses in these materials. Reduced graphene oxide (RGO), which only dis plays inter particle porosity but does not have any inter layer cross linked galleries, has been studied as a control material. Pillared graphene hydrogel using 1,6 diaminohexane $(6 \mathrm{GH})$ with 3D porous network is also synthesized as a control material to inves tigate the role of porosity in 6 RP. EIS data of the materials have been analyzed using conventional Nyquist and Bode plots and a new set of analyses (evolution of imaginary part of capacitances vs. real impedances) is also proposed to investigate their ion transport characteristics.

\section{Experimental methods}

The pillared graphene based materials studied here were pre pared using graphene oxide as a precursor with alkyldiamines as pillars [24]. The amine groups react with oxygen containing func tions such as epoxide and carboxylic acid on GO and bridge GO sheets together (Scheme 1) [25]. Graphene oxide (GO), used as a precursor for pillared graphene materials, was synthesized using a modified Hummers Offeman's method [28,29]. GO sheets were first reacted with respective diamines to form cross linked gra phene materials which are then chemically reduced with hydrazine to form reduced pillared materials (RPs) (Scheme 1) [30,31]. Depending on the diamine used in the first step, materials were named as 5 RP (1,5 diaminopentane) and 6 RP (1,6 diaminohexane). RGO was synthesized by a direct chemical reduction of GO with hydrazine hydrate. $6 \mathrm{GH}$ was synthesized by treating GO and 1,6 diaminohexane at $180^{\circ} \mathrm{C}$ in a sealed autoclave. The detailed syntheses protocols are published elsewhere and a brief description can be found in supplementary information [24]. Electrodes were fabricated by preparing an ink using a $\mathrm{N}$ methyl 2 pyrrolidone (NMP) slurry of the synthesized materials (80\%) with polyvinylidene fluoride binder (10\%) and carbon black (10\%) conductive additive. This ink is drop casted on stainless steel disks of $0.4 \mathrm{~cm}^{2}$ area and dried at $65^{\circ} \mathrm{C}$ under air for $6 \mathrm{~h}$ followed by $80^{\circ} \mathrm{C}$ under vacuum overnight. The dried electrode specific weights were around $3-4 \mathrm{mg} / \mathrm{cm}^{2}$.

Electrochemical analyses of the materials were performed in three electrode cell configuration using a silver wire as the quasi reference electrode, an overcapacitive (10 times by weight) YP50 porous carbon pellet as counter electrode and $20 \mu \mathrm{m}$ cellulose piece as the separator in Swagelok ${ }^{\circledR}$ cells. $1 \mathrm{M}$ tetraalkylammonium tet rafluoroborate $\left(\mathrm{TAABF}_{4}\right)$ salt solutions in acetonitrile with constant anion size and varying cation sizes; ethyl ( $\left.\mathrm{TEABF}_{4}\right)$, propyl (TPABF 4$)$, butyl $\left(\mathrm{TBABF}_{4}\right)$ and hexyl $\left(\mathrm{THABF}_{4}\right)$ were used as electrolytes. The unsolvated sizes of the electrolyte ions tested are $\mathrm{TEA}^{+}-0.68 \mathrm{~nm}$, $\mathrm{TPA}^{+}-0.76 \mathrm{~nm}, \mathrm{TBA}^{+}-0.82 \mathrm{~nm}, \mathrm{THA}^{+}-0.95 \mathrm{~nm}$ and $\mathrm{BF}_{4}^{-}-$ $0.48 \mathrm{~nm}$. Anhydrous acetonitrile and electrochemical grade elec trolyte salts for the study were purchased from Sigma Aldrich. Electrochemical cells were assembled inside an Ar filled glovebox and once sealed have been electrochemically tested outside using a VMP 3 potentiostat device from Bio Logic. Prior to EIS measure ments, the cells have been cycled at $50 \mathrm{mV} / \mathrm{s}$ scan rates in CVs until the electrolyte wets the whole porous material volume and the electrochemical signature reached gets a steady state - the area under the curve stabilizes ( 100 cycles). For EIS measurements, cells were held at $+1 \mathrm{~V}$ or $1 \mathrm{~V}$ vs. Ag in this 3 electrode configu ration until the current is almost null and then studied with sinu soidal voltage amplitude of $5 \mathrm{mV}$ within a frequency range spanning from $100 \mathrm{kHz}$ to $10 \mathrm{mHz}$. Obtained impedance values

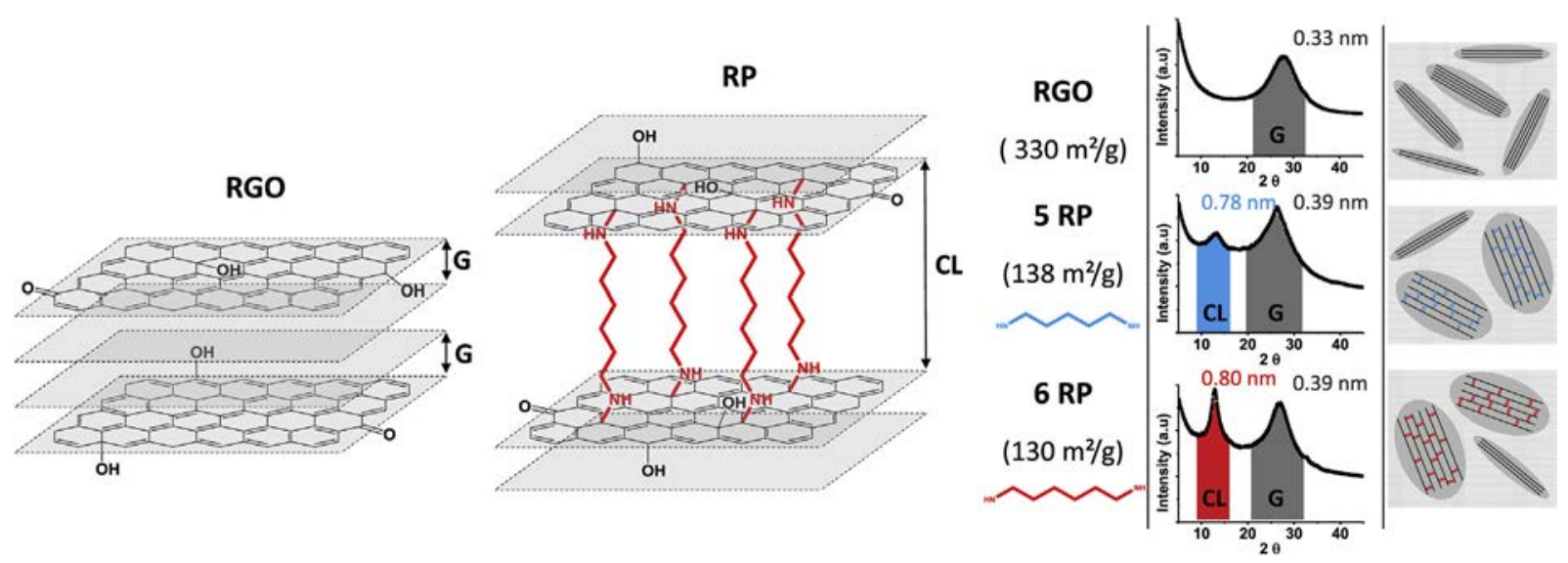

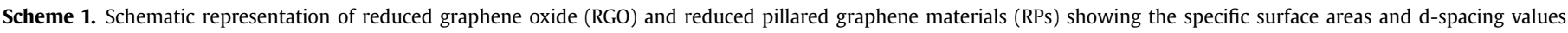
determined from XRD. XRD patterns adapted with permission from Chem. Mater. 30, 2018, 3040-3047. Copyright (2018) American Chemical Society [24]. 
were normalized with electrode weights for plotting.

\section{Results and discussion}

\subsection{Reduced pillared materials: characteristics}

In our previous work, pillared graphene structures in RPs were analyzed using a combination of spectroscopic and electrochemical characterization methods (Fig. S1) [24-26]. X ray diffraction (XRD) patterns of RGO, synthesized as a control, showed a broad peak around $28^{\circ}$ corresponding to the graphite like arrangement (002) with an inter graphene sheet distance of $0.37 \mathrm{~nm}$ (Fig. S1a). This graphite like arrangement suggested an efficient reduction of GO leading to a partial restacking of the reduced graphene sheets [32]. Whereas, the XRD patterns of RPs displayed two peaks corre sponding to partial graphitic restacking $\left(\sim 25^{\circ}\right)$ and diamine induced pillaring of graphene layers $\left(\sim 15^{\circ}\right)$. Thus, RPs demonstrate pillared structures characterized with d spacing of $0.78 \mathrm{~nm}$ in $5 \mathrm{RP}$ and $0.80 \mathrm{~nm}$ in $6 \mathrm{RP}$. The $\mathrm{N}_{2}$ gas sorption analyses have assigned a high SSA of $330 \mathrm{~m}^{2} / \mathrm{g}$ for RGO and lower values of $\sim 330 \mathrm{~m}^{2} / \mathrm{g}$ for RPs. Lower surface areas in RPs compared to RGO could arise from excessive inactive weight of alkyldiamines in RPs, structural changes during degassing and the diamine pillars may also steri cally hinder the gas molecules and render the inter layer gallery pores inaccessible [33,34]. The pore size distributions (PSDs), calculated using 2D non local density functional theory (2D NLDFT), attribute high volume of micropores and a significant contribution of mesopores for RGO and a high mesopore content with some micropores in RPs (Fig. S1c) [35].

The electrochemical responses of RGO and RPs in various elec trolytes with increasing cation sizes and constant anion size investigated the ion sieving effect in pillared graphene materials (Fig. 1). CVs of RGO and RPs showed similar rectangular quasi ideal capacitive behavior in $\mathrm{TEABF}_{4}$ but, an increase in cation size from $\mathrm{TPABF}_{4}$ to $\mathrm{TBABF}_{4}$ and $\mathrm{THABF}_{4}$ resulted in current decay under negative polarizations for RPs (Fig. 1 \& Fig. S2a). Thus, the access to inter layer gallery pores in RPs is regulated by the $\mathrm{d}$ spacing/ion size couple whereas RGO doesn't have any pillared structures and hence, exhibits similar curves in different electrolytes. The calcu lated capacitances values were lower in RPs when the inter layer graphene galleries have a smaller d spacing than the ion sizes, implying that the galleries restrict larger ions (Fig. S2b). For instance, $5 \mathrm{RP}$ shows a specific capacitance of $130 \mathrm{~F} / \mathrm{g}$ in $\mathrm{TEABF}_{4}$ but when larger cations were used, a steep decline from $115 \mathrm{~F} / \mathrm{g}$ $\left(\mathrm{TPABF}_{4}\right)$ to $42 \mathrm{~F} / \mathrm{g}\left(\mathrm{THABF}_{4}\right)$ is noted. Whereas, RGO, which adsorbs ions only at the surface of graphene layers (SSA $330 \mathrm{~m}^{2} / \mathrm{g}$ ), ex hibits similar capacitances of $\sim 110 \mathrm{~F} / \mathrm{g}$ in all the electrolytes studied. In short, this electrochemical study revealed ion sieving based on ion sizes inside the pillared graphene materials [24].

\subsection{Impedance studies: Nyquist plots}

To further characterize this ion sieving and also to gain insights into the ion transport inside the graphene galleries, EIS measure ments were performed on RGO and RPs under negative and posi tive polarizations. The normalized complex plane Nyquist plots are displayed in Fig. 2. These plots can be divided into three regions [36-38]. At high frequencies, only the electrical conductivity of the electrode (ionic and electronic) can be seen; thus, SC electrodes behave like a resistor $(Z " \quad 0)$. The sharp increase of the imaginary part of the impedance ( $\left.Z^{\prime \prime}\right)$ in the low frequency region where the plot is nearly parallel to the y axis is related to a capacitive behavior. The intermediate $45^{\circ}$ region is associated to the ion transport in the porous network of the electrode that corresponds to the electrolyte resistance in the pores.

At $1 \mathrm{~V}$ vs. $\mathrm{Ag}$, the electrodes are negatively polarized with respect to open circuit voltages (OCV) and cations are predomi nantly adsorbed at the electrode surfaces [39]. The Nyquist plots show differences between RGO and RPs in all the electrolytes tested (Fig. 2a-c). Firstly, in each electrolyte, as compared to RGO, RPs show a larger electrolyte resistance in the porous electrode network that extend into lower frequencies. Due to this resistance, the low frequency capacitive behavior in RPs shifts into higher re sistances. Secondly, with increasing cation size, the vertical line indicating capacitance in each RP gradually diverges away from the ideal $90^{\circ}$. The extent of this deviation from the ideal capacitance can be estimated by replacing the capacitance $C$ with a Constant Phase Element (CPE, see Equation (1)) using $\alpha$ parameter [40]. $\alpha$ values are obtained by measuring the slopes in equation (1) at low frequencies.

$\log \left(\left|z^{\prime \prime}(w)\right|\right) \quad \alpha \cdot \log (C \omega) \quad 0<\alpha<1$

A value of 1 for $\alpha$ indicates a fully capacitive behavior of the material. 6 RP shows decline of $\alpha$ values from 0.87 in $\mathrm{TEABF}_{4}$ to 0.77 in $\mathrm{TBABF}_{4}$ while, $5 \mathrm{RP}$ shows low value of $\sim 0.80$ in all the electro lytes indicating a non ideal capacitive behavior (Table S1). Thus, there is an important influence of the cation size on the frequency responses of RPs under negative polarization. RGO exhibits $\alpha$ values close to 1 from $\mathrm{TEABF}_{4}$ (0.95) to $\mathrm{TBABF}_{4}$ (0.93) electrolytes, evidencing a faster ion transport in the pores.

Ion sorption in RGO occurs in the micro/meso inter particle pores and thus the $\mathrm{TEA}^{+}, \mathrm{TPA}^{+}$and $\mathrm{TBA}^{+}$cations access them with relative ease. Therefore, the impedance measurements of RGO show ideal capacitive like behavior and do not vary a lot in these electrolytes. In RPs, ion sorption occurs significantly in the inter layer porous network in addition to the inter particle pores. Ac cess to the inter layer pores in RPs is regulated by d spacing/ion size couple. Therefore, the frequency responses of RPs are
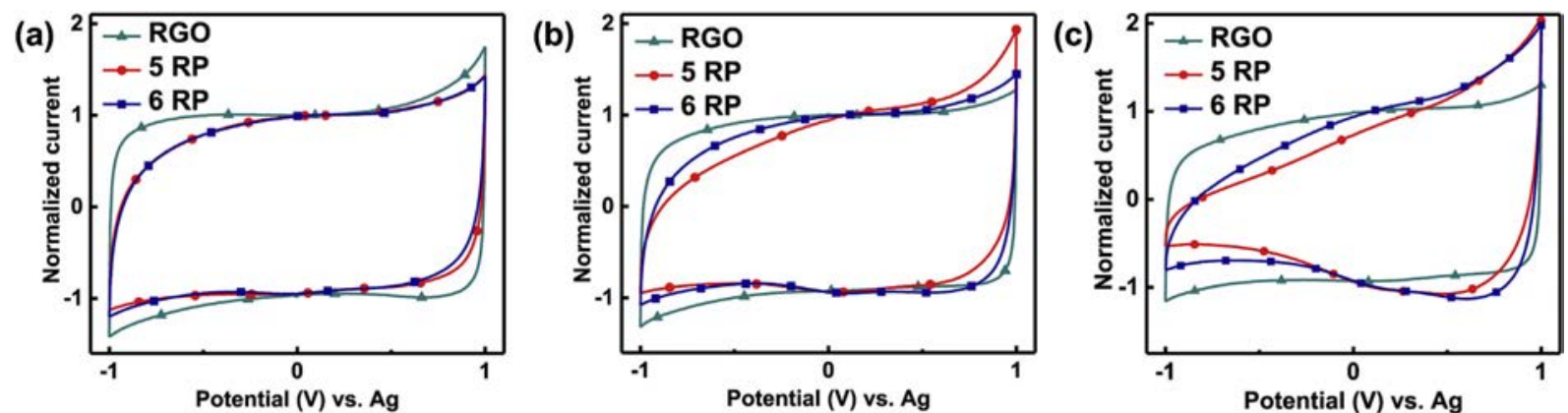

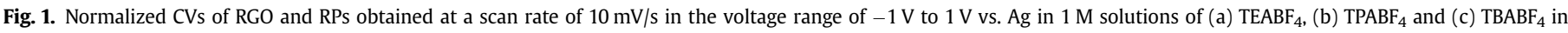
acetonitrile. Normalization was performed with respective currents observed at open circuit voltages $(\sim 0.1 \mathrm{~V})$. 
$-1 \mathrm{~V} v \mathrm{vs}$. Ag

(a)

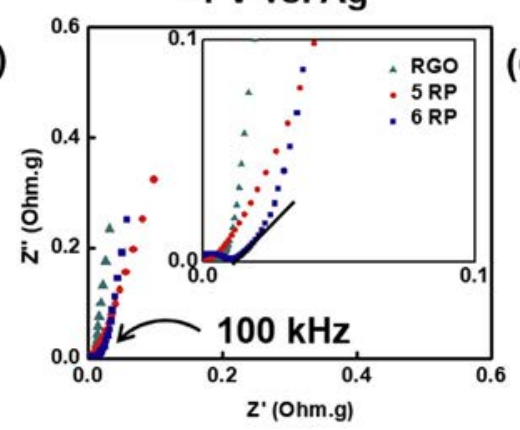

(b)

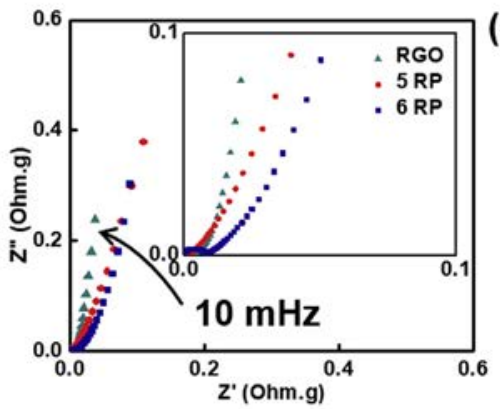

(c)

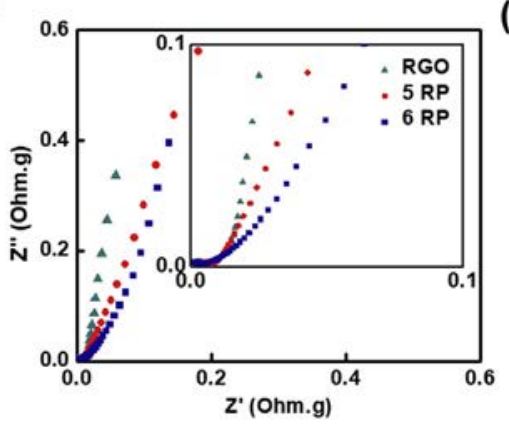

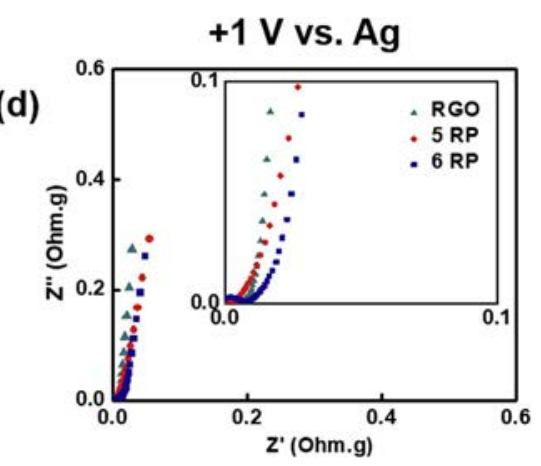

(e)
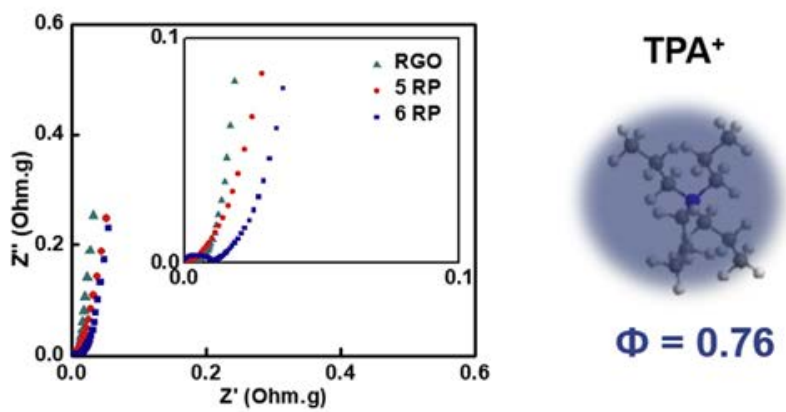

(f)

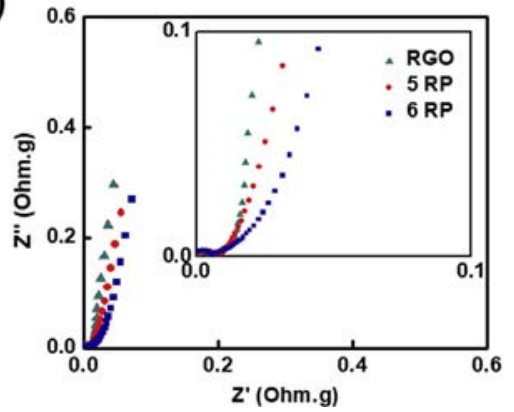

TEA $^{+}$

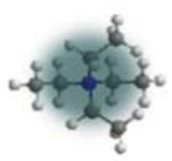

$\Phi=0.68$
$\Phi=0.76$

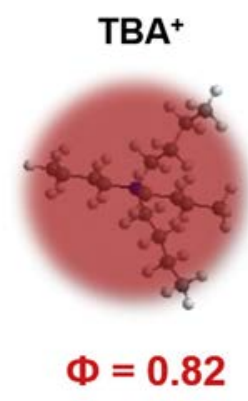

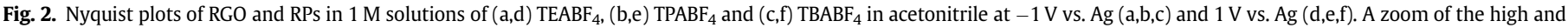
mid-frequency regions is shown in the insets. Unsolvated ion sizes of TEA ${ }^{+}, \mathrm{TPA}^{+}$and $\mathrm{TBA}^{+}$are shown on the right.

dependent on their $\mathrm{d}$ spacing and the effective size of the elec trolyte ions. $6 \mathrm{RP}$, with a d spacing of $0.80 \mathrm{~nm}$, has a performance similar to that of RGO in $\mathrm{TEABF}_{4}$ but extended diffusion regions are seen with larger cations. Impedance data in $\mathrm{THABF}_{4}$ electrolyte further supports the different ion sorption mechanisms for RGO and RPs (Fig. S3a). In RPs, $\mathrm{THA}^{+}$cation $(0.95 \mathrm{~nm})$ is larger than the $\mathrm{d}$ spacing values, like with $\mathrm{TBA}^{+}$, and hence even larger imped ances were recorded. Notably, RGO possesses a major contribution from inter particle pores with a diameter of $\sim 0.9 \mathrm{~nm}$ and thus only when $\mathrm{THA}^{+}$cations are used, a sudden increase in the Warburg region and decrease in $\alpha$ parameter $(0.83)$ are observed (Table S1).

At $+1 \mathrm{~V}$ vs. Ag, the materials are positively polarized with respect to open circuit voltages and $\mathrm{BF}_{4}^{-}$ions are predominantly adsorbed on the electrode surfaces. The Nyquist plots of RGO and RPs show similar shapes among themselves in the three different electrolytes tested (Fig. $2 \mathrm{~d}-\mathrm{f}$ ). The $\mathrm{BF}_{4}^{-}$ions are smaller than the gallery pores in RPs and hence display capacitive like behavior similar to RGO. However, the vertical part in the low frequency region slightly shifts away from the ideal behavior from $\mathrm{TEABF}_{4}$ to $\mathrm{TBABF}_{4}$. $\alpha$ values for RGO range from 0.97 to 0.95 whereas RPs range from 0.93 to 0.86 in $\mathrm{TEABF}_{4}$ to $\mathrm{TBABF}_{4}$ (Table $\mathrm{S} 1$ ). This interesting shift from ideal behavior despite analyzing the same $\mathrm{BF}_{4}^{-}$ions in different electrolytes hints at a possible role of cations even under positive polarization, such as previously observed [41]. In summary, RGO and RPs show similar responses in all electrolytes under positive potentials and an increasing influence of larger cations, in addition to anions, is also noted. This observation was described as an ion exchange mechanism in earlier reports [41-43]. With the largest cation in $\mathrm{THABF}_{4}, \alpha$ values of RGO and RPs decrease to 0.90 and 0.76 respectively, indicating a greater cation exchange effect.

\subsection{Impedance studies: complex capacitance analysis}

In order to further explore the frequency responses of the syn thesized materials, we performed a complex capacitance analysis that was proposed by Taberna et al. and derived from Cole and Cole [44-46]. In the proposed analysis, complex capacitance is studied in order to focus on the capacitive behavior and ionic resistance within the active material. The closest equivalent circuit repre sentation of the capacitor in this analysis has a series resistance, Rs, together with an angular frequency dependant $R_{p} C_{p}$ bridge: a combination of resistance, $R_{p}(\omega)$, in parallel with a capacitance, $\mathrm{C}_{\mathrm{p}}(\omega)$ (Fig. S5).

This complex analysis allowed determination of the real capacitance, $C^{\prime}(w)$, which represents the deliverable capacitance of the cell under $\mathrm{DC}$ or low frequency $\mathrm{AC}$ conditions. $\mathrm{C}^{\prime}(w)$ is 
calculated using equation (2), where $Z^{\prime \prime}(w)$ is the imaginary part of impedance $\mathrm{Z}$ and $w$ is the frequency.

$C^{\prime}(w) \quad \frac{z^{\prime \prime}(w)}{w|\mathrm{z}(\mathrm{w})|^{2}}$

The evolution of $C^{\prime}$ with respect to frequency for each sample at $1 \mathrm{~V}$ and $1 \mathrm{~V}$ vs. Ag was plotted accordingly (Fig. 3). At higher frequencies, the system acts as a pure resistor with capacitance values close to zero and at lower frequencies, a pure capacitive behavior is seen as a plateau if the maximal $\mathrm{C}^{\prime}$ occurs in the tested frequency range. The intermediate zone gives information about electrolyte access to the electrode porosity (gallery and inter particle pores) [44].

At $1 \mathrm{~V}$ vs. Ag, $\mathrm{C}^{\prime}$ vs $w$ plots for RGO approach a maximal $\mathrm{C}^{\prime}$ plateau in $\mathrm{TEABF}_{4}, \mathrm{TPABF}_{4}$ and $\mathrm{TBABF}_{4}$ at the lowest frequency tested $(10 \mathrm{mHz})$, revealing a fast transport of electrolytic ions in the electrode material (Fig. 3a-c). However, in $\mathrm{THABF}_{4}$, RGO displays lower $\mathrm{C}^{\prime}$ values and a non ideal behavior as the cation size ap proaches the inter particle pore sizes in RGO (Fig. S4a). For 6 RP, $\mathrm{C}^{\prime}$ is closely equivalent to that of RGO in $\mathrm{TEABF}_{4}$ and increasing cation sizes shifts the pure capacitive behavior to lower frequencies. $5 \mathrm{RP}$, even in $\mathrm{TEABF}_{4}$, does not approach a plateau and the ion transport is gradually limited in other electrolytes. Additionally, with larger cations in RPs, the maximal $\mathrm{C}^{\prime}$ values and the slopes in the inter mediate region gradually decrease.

This EIS data under negative polarization really shows a slower ion transport in RPs when larger cations are used. In RPs, steric effects when ion size is in the same range as the inter layer gallery size lead to limited ion transport and accessibility to adsorption sites. Thus, with a complex dynamic process, RPs do not reach a plateau with full capacitance in this frequency range and confirm resistive behavior. At $+1 \mathrm{~V}$ vs. Ag, RGO and RPs all show curves with similar maximal $C^{\prime}$ values and slopes in the intermediary region (Fig. 3d-f). However, with increasing cation size, it can be noted that the plateaus of $C^{\prime}$ slightly drift towards lower frequencies. This observation, as noted in the Nyquist plots, could be seen as an in fluence of cations via the existence of an ion exchange mechanism [41]. Results obtained with $\mathrm{THABF}_{4}$ under positive potential show a steep fall of $\mathrm{C}^{\prime}$ values in all the materials, supporting this effect (Fig. S4b). Moreover, an increase in the alkyl chain length from $\mathrm{TEA}^{+}$to $\mathrm{THA}^{+}$ions could give rise to stronger interactions between graphene sheets and alkyl carbons of the electrolytic ions, resulting in enhanced influence of cations.

The complex capacitance model also allows the determination of imaginary capacitance $\left(\mathrm{C}^{\prime \prime}\right)$ which corresponds to the energy loss arising from irreversible processes at the electrodes [44]. This $C^{\prime \prime}(w)$ parameter was calculated from EIS data using equation (3), where $Z^{\prime}(w)$ is the real part of impedance $Z$ :

$C^{\prime \prime}(w) \frac{z^{\prime}(w)}{w|z(w)|^{2}}$

The imaginary $C^{\prime \prime}$ goes through a maximum at a frequency $f_{0}$ which defines the transition between purely resistive and capaci tive behaviors of a SC. This frequency, known as knee frequency, defines the time constant $\left(\tau_{0}\right)$ as minimum time required to extract half of the capacitance from a SC [45]. C" vs $w$ plots of RGO and RPs at +1 and $1 \mathrm{~V}$ vs. Ag show similar and dissimilar curves respec tively, supporting the role of ion discussed above. (Figs. S6 and S7). The $\tau_{0}$ values obtained from these curves assign better power capability for RGO than RPs (Table 1 ). Interestingly, the $\tau_{0}$ values for

Table 1

Time constant $\left(\tau_{0}\right)$ values (seconds) of RGO and RPs were calculated from the frequencies at which maximum values of $\mathrm{C}^{\prime \prime}$ occurred.

\begin{tabular}{|c|c|c|c|c|c|c|c|c|}
\hline \multirow[t]{2}{*}{ Material } & \multicolumn{2}{|c|}{$\mathrm{TEABF}_{4}$} & \multicolumn{2}{|c|}{$\mathrm{TPABF}_{4}$} & \multicolumn{2}{|c|}{$\mathrm{TBABF}_{4}$} & \multicolumn{2}{|c|}{$\mathrm{THABF}_{4}$} \\
\hline & $+1 \mathrm{~V}$ & $-1 \mathrm{~V}$ & $+1 \mathrm{~V}$ & $-1 \mathrm{~V}$ & $+1 \mathrm{~V}$ & $-1 \mathrm{~V}$ & $+1 \mathrm{~V}$ & $-1 \mathrm{~V}$ \\
\hline RGO & 6 & 6 & 6 & 6 & 6 & 6 & 7 & 12 \\
\hline $5 \mathrm{RP}$ & 7 & & 10 & & 11 & & & \\
\hline $6 \mathrm{RP}$ & 10 & 15 & 16 & 25 & 20 & 32 & 41 & \\
\hline
\end{tabular}
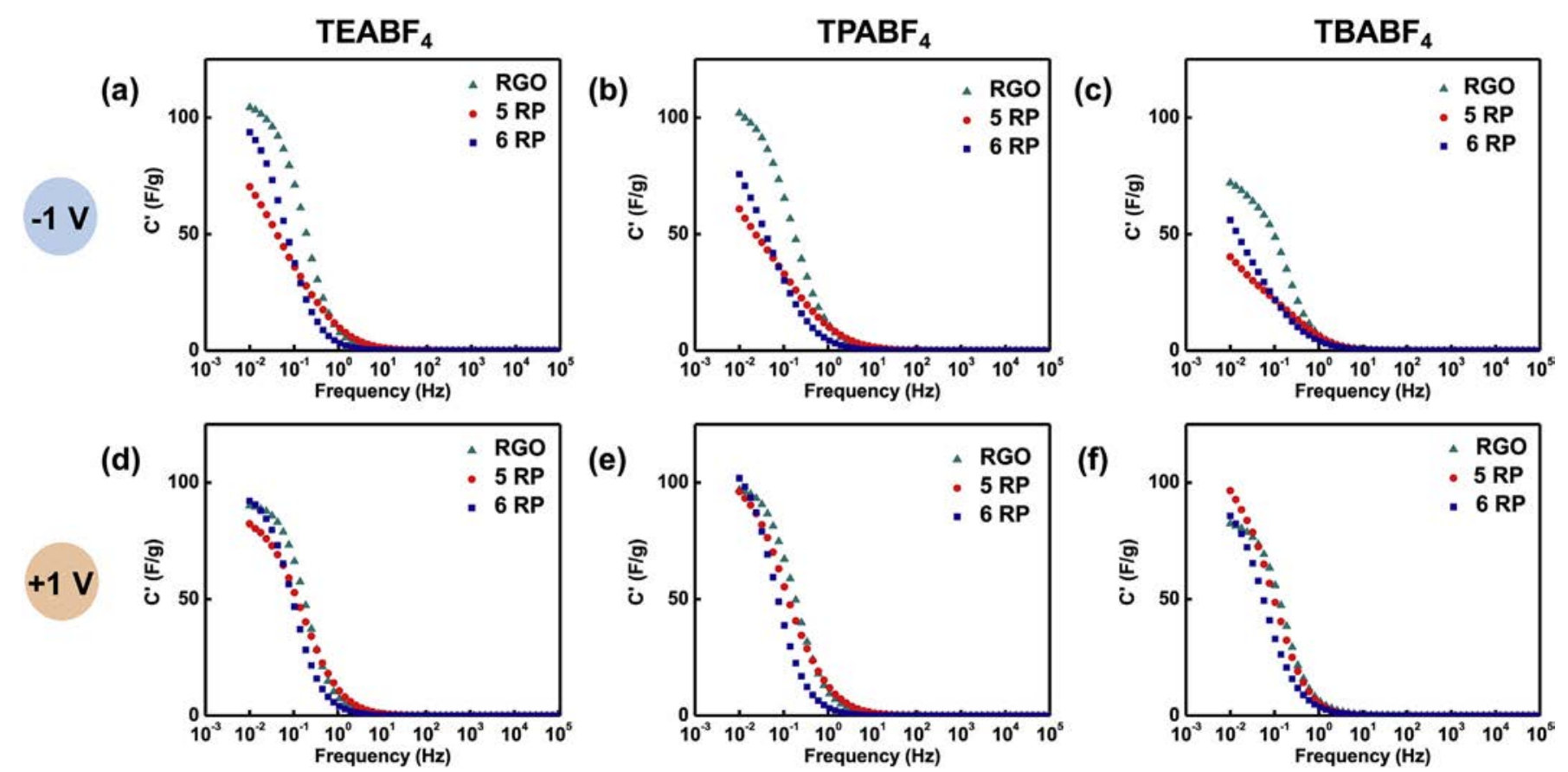

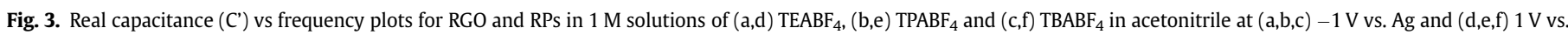
Ag. 
$5 \mathrm{RP}$ are lower than for $6 \mathrm{RP}$ in all the electrolytes tested under positive polarization [45]. For example, $\tau_{0}$ of 5 and 6 RPs in $\mathrm{TBABF}_{4}$ are 11 and $20 \mathrm{~s}$ respectively. This difference between RPs is counter intuitive as one would expect $6 \mathrm{RP}$, with a higher $\mathrm{d}$ spacing, to facilitate better transport and lower $\tau_{0}$ value for $\mathrm{BF}_{4}^{-}$anion. As $\tau_{0}$ values are affected by a combination of ionic, electrical and cell resistances, it seems important to determine the distinct impact of the material properties on ionic resistances.

To do so, herein, we studied $C^{\prime \prime}$ with respect to $Z^{\prime}$. We believed that such an analysis could enable facile quantitative determination of the effective ionic resistances $\left(\mathrm{R}_{\mathrm{i}}\right)$ involved in ion transport. The $R_{i}$ values directly obtained here could be seen as equivalent to the one third of the in pore ionic resistance calculated by employing the Transmission Line Model [47]. Similar to other plots, three different regions could be identified in such a curve (Fig. 4). At high frequencies the SC performs like a resistor and $C^{\prime \prime}$ would be close to zero (from Eq. (3)). The mid frequency range is related to the ion transport inside the electrode porous structure hence, a steep in crease in $\mathrm{C}^{\prime \prime}$ would be seen since there is no dielectric loss in an ideal capacitance when $\omega \rightarrow 0$. At low frequencies, an ideal SC would display a steep fall in $C^{\prime \prime}$ (from Eq. (3)). The $R_{i}$ values were obtained from the real $\mathrm{Z}$ values at the start and end of the mid range frequencies.

The $\mathrm{C}^{\prime \prime}$ vs $\mathrm{Z}^{\prime}$ plots at $1 \mathrm{~V}$ vs. Ag show a clear difference between RGO and RPs in TEABF 4 , TPABF 4 and $\mathrm{TBABF}_{4}$ (Fig. 4a-c). The re sponses of RGO and RPs in various frequency regions and their evolution in electrolytes could be distinctly identified here compared to Nyquist and Bode plots. RGO displays curves with a clear maxima of $\mathrm{C}^{\prime \prime}$ occurring at a low resistance and then rapidly decreasing along the $x$ axis. The calculated $R_{i}$ show close values of around 10 mOhm.g from TEABF 4 to $\mathrm{TBABF}_{4}$ (Fig. 4g). 6RP Ri is closely equivalent to that of RGO in $\mathrm{TEABF}_{4}$ (Fig. 4a) but, with larger cations, the $C^{\prime \prime}$ extends to even higher resistances and eventually shows a continuous plateau with $\mathrm{TBABF}_{4}$ (Fig. 4c). The plateau symbolizes an extended limitation of ion transport inside the porous electrode while the cell is not reaching a capacitor like behavior. This increasingly resistive behavior of 6 RP with larger cations is quantified with rise in $\mathrm{R}_{\mathrm{i}}$ values from $20 \mathrm{mOhm} . \mathrm{g}$ in $\mathrm{TEABF}_{4}$ to $70 \mathrm{mOhm}$.g in $\mathrm{TBABF}_{4} .5 \mathrm{RP}$ plot shows continuous plateau with no transition peak even with the smallest cation tested in $\mathrm{TEABF}_{4}$ and already shows a high $\mathrm{R}_{\mathrm{i}}$ of $55 \mathrm{mOhm} . \mathrm{g}$ (Fig. 4a). Further increase in cation sizes lead to even higher $\mathrm{R}_{\mathrm{i}}$ up to 172 mOhm.g in $\mathrm{TBABF}_{4}$ (Fig. 4c). This continuous loss of energy even at the low frequencies led us to examine the leakage currents for all cells. The measured leakage currents show similar values for RGO and RPs in all electrolytes and suggest that the observed continuous energy losses are characteristics of the materials (Table S2). At $+1 \mathrm{~V}$ vs. Ag, RGO and RPs show similar curves, however, occurring at different values of real $\mathrm{Z}$ (Fig. $4 \mathrm{~d}-\mathrm{f}$ ). The $\mathrm{C}^{\prime \prime}$ values for RPs occur at greater resistances than RGO indicating greater irreversible energy losses. Among the two RPs, 6 RP has slightly larger ionic resistances than $5 \mathrm{RP}$ in all the electrolytes

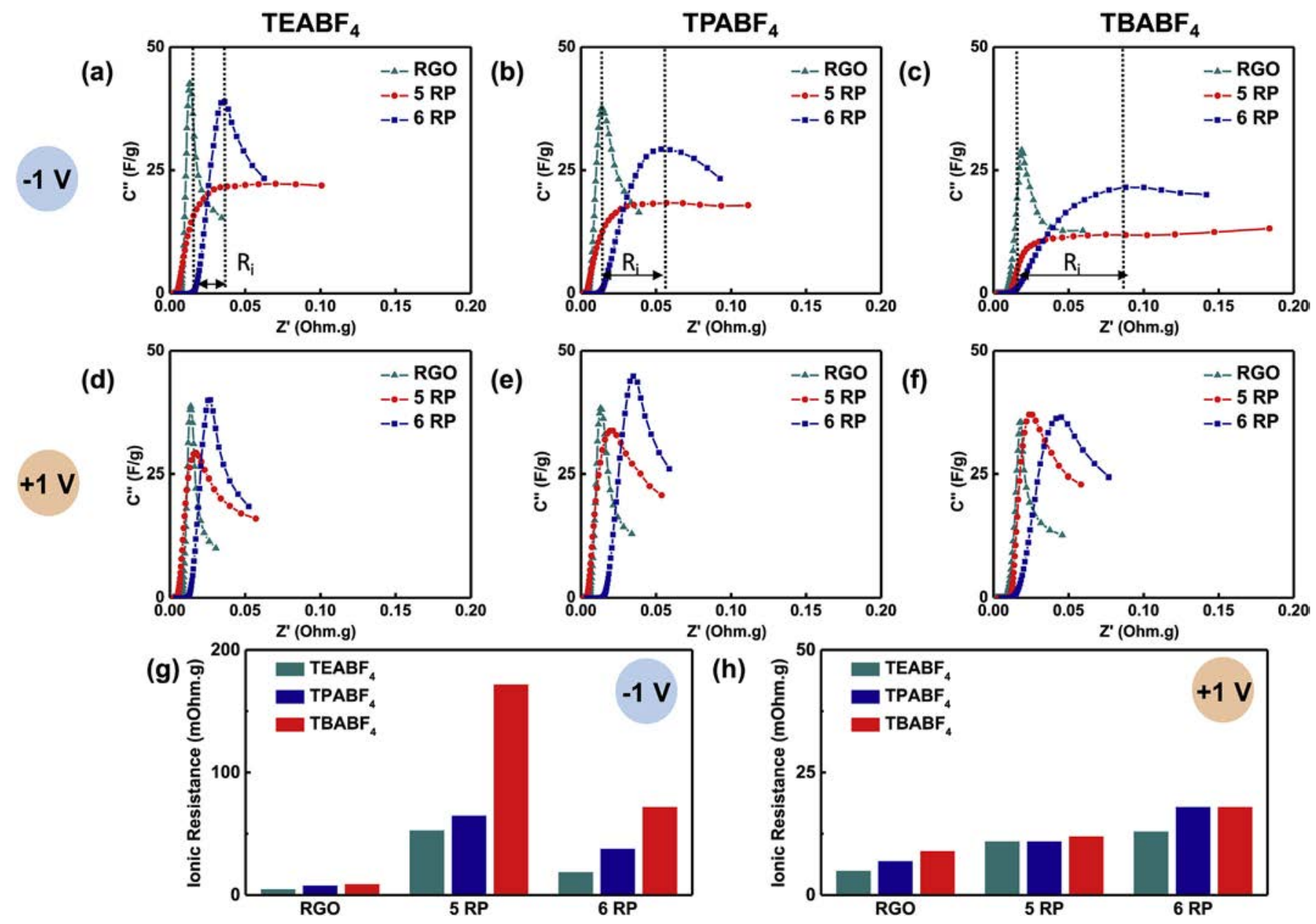

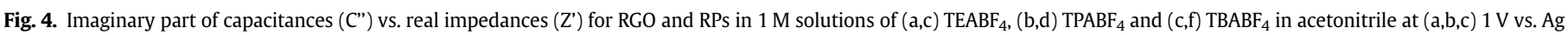

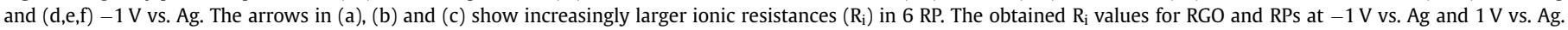


(Fig. 4h). This resistive behavior of 6 RP supports the earlier observed greater $\tau_{0}$ values than $5 \mathrm{RP}$. We speculate that the conformation (trans \& gauche) of the diamines inside the gallery could be the reason behind this behavior. It has been reported that with increasing alkyl chains lengths in the diamine the ratio of trans gauche conformations shifts towards higher trans content [25]. Hexanediamine (in 6 RP) may locally occupy higher volume in the gallery than pentanediamine (in $5 \mathrm{RP}$ ) and thus have higher ionic resistances. Moreover, the odd and even number of carbons in the diamines used here could also affect the overall polarity and ion sorption in the gallery. The cation sorption at $1 \mathrm{~V}$, masks these fine details among RPs as the steric effects result in large $R_{i}$ values. As the $R_{i}$ values at $+1 \mathrm{~V}$ are smaller, this subtle influence of the alkyl chain conformation on 5 and 6 RPs is seen distinctly. Overall, the proposed $C^{\prime \prime}$ vs. $Z^{\prime}$ plots show an amplified difference between the materials compared to Nyquist, Bode plots or other representation proposed by Pickup et al. [48]. It is also noteworthy that we obtain effective ionic resistances directly from the experimental data without using TLM or PSD TLM models $[47,49]$.

\subsection{Investigating role of porosity}

Earlier analysis of capacitance values from CVs have shown marginally higher values for RPs than for RGO with appropriately smaller ions (TEABF 4 ). However, even in the case of $\mathrm{TEABF}_{4}$, the impedance analysis has indicated that RPs exhibit sluggish ion transport relative to RGO. This could be explained by hindered mobility of the ions in the galleries due to unadapted porosity or the presence of alkyl diamine pillars. To investigate if the impeded ion transport is arising from unsuited porous network, we syn thesized and analyzed a pillared graphene hydrogel (GH) that has a 3D percolating network using 1,6 hexanediamine as the pillar $(6 \mathrm{GH})$ (details in SI). The 3D percolating network offers multiple ion pathways and is known to show enhanced ion transport char acteristics in the hydrogels [22]. The $\mathrm{N}_{2}$ gas sorption isotherms and corresponding PSDs characterize $6 \mathrm{GH}$ with enhanced micro and meso pores compared to $6 \mathrm{RP}$ (Fig. S9 a\&b). The calculated SSAs indicate increase in the values from $130 \mathrm{~m}^{2} / \mathrm{g}$ in $6 \mathrm{RP}$ to $182 \mathrm{~m}^{2} / \mathrm{g}$ in 6 GH (Table S3). Scanning electron microscopic images also reveal more open macro porosity in $6 \mathrm{GH}$ than $6 \mathrm{RP}$ (Fig. S9 c\&d). Addi tionally, $6 \mathrm{GH}$ shows greater $\mathrm{d}$ spacing of $0.86 \mathrm{~nm}$ compared to $0.80 \mathrm{~nm}$ of $6 \mathrm{RP}$ probably due to the stronger reaction conditions and diamine consumption during $6 \mathrm{GH}$ synthesis. The TGA profiles of the two materials support this explanation with a greater weight loss due to decomposition of covalently attached diamines.

Electrochemical analysis of $6 \mathrm{GH}$ in $1 \mathrm{M} \mathrm{TEABF}_{4}$, which has sufficiently smaller ions than the d spacing, shows slightly higher capacitances of $142 \mathrm{~F} / \mathrm{g}$ than $6 \mathrm{RP}(130 \mathrm{~F} / \mathrm{g})$ and RGO $(117 \mathrm{~F} / \mathrm{g})$. This shows that the 3D assembly with improved SSAs, along with the cross linking at nanoscale, yields enhanced capacitances in these pillared materials. However, the impedance analysis under nega tive polarizations shows that the ion motion remains very much impeded in $6 \mathrm{GH}$ despite its 3D structure and the larger $\mathrm{d}$ spacing $(0.86 \mathrm{~nm})$ (Fig. $5 \mathrm{a}$ and $\mathrm{b})$. In fact, the obtained $\mathrm{R}_{\mathrm{i}}$ and $\tau_{0}$ values show greater resistances in $6 \mathrm{GH}$ with higher values of $57 \mathrm{mOhm} . \mathrm{g}$ and $23 \mathrm{~s}$ compared to $20 \mathrm{mOhm} . \mathrm{g}$ and $17 \mathrm{~s}$ for $6 \mathrm{RP}$ (Table S3). These observations suggest that the alkyl diamine pillars inside the gal leries play an important role in ion transport between the graphene layers. Moreover, the obtained capacitances of both $6 \mathrm{RP}$ and $6 \mathrm{GH}$ are only slightly better than RGO despite enhanced ion access to the cross linked galleries. This is possibly due to excessive filling of the galleries with diamine pillars leading to impeded ion transport to active sites. This understanding of the impact of pillars and the porosity provides new strategies to improve energy and power
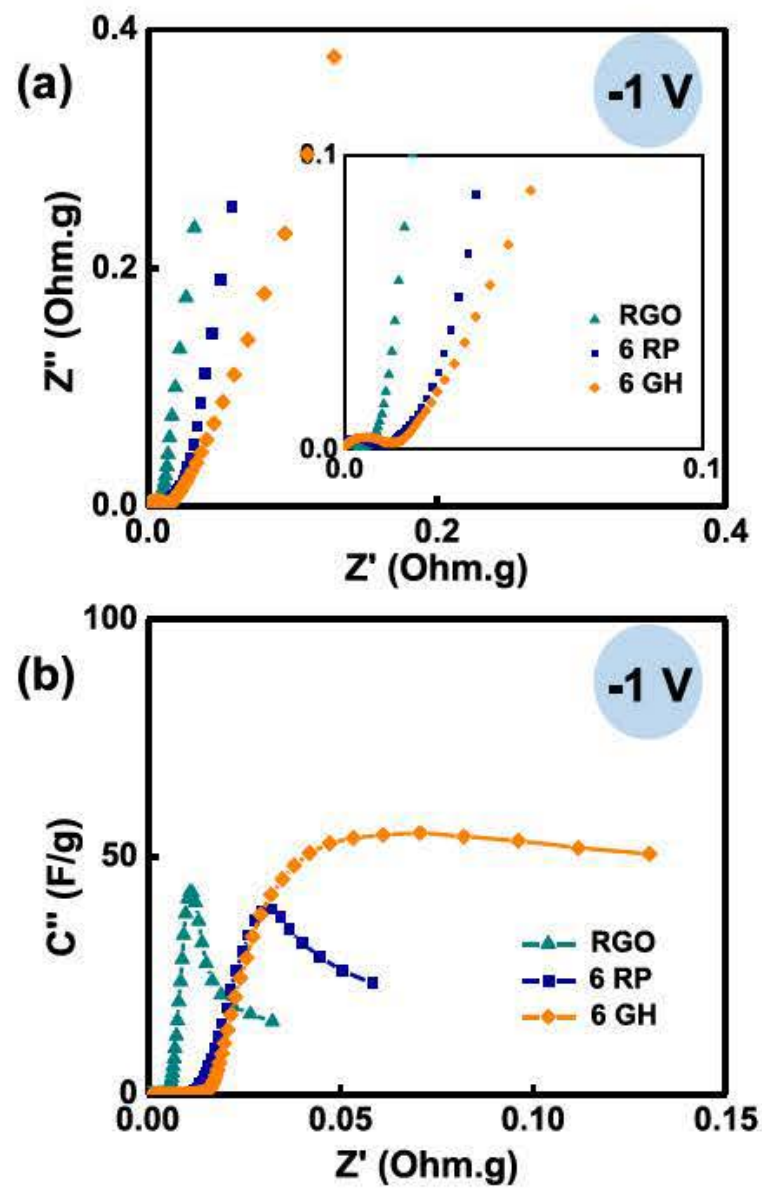

Fig. 5. (a) Nyquist plots and (b) Imaginary part of capacitances vs. real impedance plots of RGO, $6 \mathrm{RP}$ and $6 \mathrm{GH}$ in $1 \mathrm{M}$ solution of $\mathrm{TEABF}_{4}$ at $-1 \mathrm{~V}$ vs. $\mathrm{Ag} \mathrm{A}$ zoom of the high frequency regions in Nyquist plot is shown in the inset.

densities of pillared materials. Decreasing the number of pillars between the graphene layers could be a straightforward strategy for enhanced power and energy values. Integrating additional inter particle pores could be another strategy for enhancement of energy densities. Collectively, pillared materials with low pillar density and additional inter particle pores could offer both high energy and power densities.

\section{Conclusions}

Impedance measurements have been performed to investigate the ion transport dynamics in pillared graphene based materials. A range of electrolytes with increasing cation sizes and a constant anion size were studied under positive and negative electrode polarizations. Depending on the cation size, Nyquist and Bode plots of RPs exhibited large Warburg like regions and delayed capacitive behaviors whereas RGO responses remained similar. Ionic re sistances obtained through original $C^{\prime \prime} v s$. $Z^{\prime}$ plots enabled a quan titative analysis of these observations and show that the ion transport in RPs is mainly controlled by graphene inter layer gallery sizes. As RPs sieve ions into the pillared graphene layers, steric ef fects impede the ion transport when ion size is in the same range as the inter layer gallery size. RGO adsorbs ions in the inter particle micro/meso pores and the ion access to the active sites is rela tively easier. The observed high ionic resistances for RPs compared to RGO are thus in accordance with the earlier CV experiments that displayed poor power capability for RPs at high scan rates. This 
knowledge from cyclic voltammetry and the dynamic ion transport between graphene layers materials opens up perspectives towards enhanced charge storage in graphene materials.

\section{Acknowledgments}

This work was supported by CEA (H. Banda) and by French ANR Program (SUGGEST ANR 15 CE05 0022). The access to mutualized equipment and PFNC Nano characterization Minatec platforms was appreciated by the authors. G. Bidan and D. Aradilla are also thanked for fruitful discussions and advices.

\section{Appendix A. Supplementary data}

Supplementary data to this article can be found online at https://doi.org/10.1016/j.electacta.2018.11.122.

\section{References}

[1] J.R. Miller, P. Simon, Electrochemical capacitors for energy management, Science 321 (2008) 651 652, https://doi.org/10.1126/science.1158736.

[2] B.E. Conway, Electrochemical Supercapacitors - Scientific Fundamentals and Technological Applications, Springer International Publishing, NewYork, 1999.

[3] P. Simon, Y. Gogotsi, Materials for electrochemical capacitors, Nat. Mater. 7 (2008) 845, https://doi.org/10.1038/nmat2297.

[4] F. Béguin, V. Presser, A. Balducci, E. Frackowiak, Carbons and electrolytes for advanced supercapacitors, Adv. Mater. 26 (2014) 2219 2251, https://doi.org/ 10.1002/adma.201304137.

[5] L.L. Zhang, X.S. Zhao, Carbon-based materials as supercapacitor electrodes, Chem. Soc. Rev. 38 (2009) 2520 2531, https://doi.org/10.1039/B813846J.

[6] G. Wang, L. Zhang, J. Zhang, A review of electrode materials for electrochemical supercapacitors, Chem. Soc. Rev. 41 (2012) 797 828, https://doi.org/ 10.1039/C1CS15060J.

[7] J. Chmiola, G. Yushin, Y. Gogotsi, C. Portet, P. Simon, P.L. Taberna, Anomalous increase in carbon capacitance at pore sizes less than 1 nanometer, Science 313 (2006) 1760 1763, https://doi.org/10.1126/science.1132195.

[8] G. Salitra, A. Soffer, L. Eliad, Y. Cohen, D. Aurbach, Carbon electrodes for double-layer capacitors I. Relations between ion and pore dimensions, J. Electrochem. Soc. 147 (2000) 2486 2493, https://doi.org/10.1149/ 1.1393557.

[9] C. Largeot, C. Portet, J. Chmiola, P.-L. Taberna, Y. Gogotsi, P. Simon, Relation between the ion size and pore size for an electric double-layer capacitor, J. Am. Chem. Soc. 130 (2008) 2730 2731, https://doi.org/10.1021/ja7106178.

[10] E. Raymundo-Pinero, K. Kierzek, J. Machnikowski, F. Béguin, Relationship between the nanoporous texture of activated carbons and their capacitance properties in different electrolytes, Carbon 44 (2006) 2498 2507, https:// doi.org/10.1016/j.carbon.2006.05.022.

[11] M. Salanne, B. Rotenbero K. Naoi, K. Kaneko, P.L Taberna, C.P. Grey, B. Dunn, P. Simon, Efficient storage mechanisms for building better supercapacitors, Nat. Energy 1 (2016) 16070.

[12] J. Chmiola, C. Largeot, P.-L. Taberna, P. Simon, Y. Gogotsi, Desolvation of ions in subnanometer pores and its effect on capacitance and double-layer theory, Angew. Chem. Int. Ed. 47 (2008) 3392 3395, https://doi.org/10.1002/ anie.200704894.

13] C. Pean, B. Daffos, B. Rotenberg P. Levitz, M. Haefele, P.-L. Taberna, P. Simon, M. Salanne, Confinement, desolvation, and electrosorption effects on the diffusion of ions in nanoporous carbon electrodes, J. Am. Chem. Soc. 137 (2015) 12627 12632, https://doi.org/10.1021/jacs.5b07416.

[14] C. Merlet, C. Péan, B. Rotenberg, P.A. Madden, B. Daffos, P.-L. Taberna, P. Simon, M. Salanne, Highly confined ions store charge more efficiently in supercapacitors, Nat. Commun. 4 (2013) 2701, https://doi.org/10.1038/ ncomms3701.

[15] R. Raccichini, A. Varzi, S. Passerini, B. Scrosati, The role of graphene for electrochemical energy storage, Nat. Mater. 14 (2015) 271, https://doi.org/ 10.1038/nmat4170.

[16] C. Liu, Z. Yu, D. Neff, A. Zhamu, B.Z. Jang, Graphene-based supercapacitor with an ultrahigh energy density, Nano Lett. 10 (2010) 4863 4868, https://doi.org/ 10.1021/nl102661q.

[17] M.D. Stoller, S. Park, Y. Zhu, J. An, R.S. Ruoff, Graphene-based ultracapacitors, Nano Lett. 8 (2008) 3498 3502, https://doi.org/10.1021/nl802558y.

[18] Y. Tao, X. Xie, W. Lv, D.-M. Tang, D. Kong, Z. Huang, H. Nishihara, T. Ishii, B. Li, D. Golberg, F. Kang, T. Kyotani, Q.-H. Yang, Towards ultrahigh volumetric capacitance: graphene derived highly dense but porous carbons for supercapacitors, Sci. Rep. 3 (2013) 2975, https://doi.org/10.1038/srep02975.

[19] J. Qu, Y. Li, S. Lv, F. Gao, C. Geng, M. Wu, Dense 3D graphene macroforms with nanotuned pore sizes for high performance supercapacitor electrodes, J. Phys. Chem. C 119 (2015) 24373 24380, https://doi.org/10.1021/acs.jpcc.5b06616.

[20] Y. Xu, Z. Lin, X. Zhong, X. Huang, N.O. Weiss, Y. Huang, X. Duan, Holey graphene frameworks for highly efficient capacitive energy storage, Nat.
Commun. 5 (2014) 4554, https://doi.org/10.1038/ncomms5554

[21] M.M. Hantel, T. Kaspar, R. Nesper, A. Wokaun, R. Kotz, Partially reduced graphite oxide for supercapacitor electrodes: effect of graphene layer spacing and huge specific capacitance, Electrochem. Commun. 13 (2011) 90 92, https://doi.org/10.1016/j.elecom.2010.11.021.

[22] C. Li, G. Shi, Functional gels based on chemically modified graphenes, Adv. Mater. 26 (2014) 3992 4012, https://doi.org/10.1002/adma.201306104.

[23] B. Sidhureddy, A.R. Thiruppathi, A. Chen, From graphite to interconnected reduced graphene oxide: one-pot synthesis and supercapacitor application, Chem. Commun. 53 (2017) 7828 7831, https://doi.org/10.1039/C7CC03060F.

[24] H. Banda, B. Daffos, S. Périé, Y. Chenavier, L. Dubois, D. Aradilla, S. Pouget, P. Simon, O. Crosnier, P.-L. Taberna, F. Duclairoir, Ion sieving effects in chemically tuned pillared graphene materials for electrochemical capacitors, Chem. Mater. 30 (2018) 3040 3047, https://doi.org/10.1021/ acs.chemmater.8b00759.

[25] M. Herrera-Alonso, A.A. Abdala, M.J. McAllister, I.A. Aksay, R.K. Prud'homme, Intercalation and stitching of graphite oxide with diaminoalkanes, Langmuir 23 (2007) 10644 10649, https://doi.org/10.1021/la0633839.

[26] W.-S. Hung, C.-H. Tsou, M. De Guzman, Q.-F. An, Y.-L. Liu, Y.-M. Zhang, C.C. Hu, K.-R. Lee, J.-Y. Lai, Cross-linking with diamine monomers to prepare composite graphene oxide-framework membranes with varying d-spacing, Chem. Mater. 26 (2014) 2983 2990, https://doi.org/10.1021/cm5007873.

[27] L. Eliad, G. Salitra, A. Soffer, D. Aurbach, Ion sieving effects in the electrical double layer of porous carbon Electrodes: estimating effective ion size in electrolytic solutions, J. Phys. Chem. B 105 (2001) 6880 6887, https://doi.org/ 10.1021/jp010086y.

[28] W.S. Hummers, R.E. Offeman, Preparation of graphitic oxide, J. Am. Chem. Soc 80 (1958), https://doi.org/10.1021/ja01539a017, 13391339.

[29] N. Ashok Kumar, S. Gambarelli, F. Duclairoir, G. Bidan, L. Dubois, Synthesis of high quality reduced graphene oxide nanosheets free of paramagnetic metallic impurities, J. Mater. Chem. A. 1 (2013) 2789 2794, https://doi.org/ 10.1039/C2TA01036D.

[30] H. Banda, D. Aradilla, A. Benayad, Y. Chenavier, B. Daffos, L. Dubois, F. Duclairoir, One-step synthesis of highly reduced graphene hydrogels for high power supercapacitor applications, J. Power Sources 360 (2017) 538 547, https://doi.org/10.1016/j.jpowsour.2017.06.033.

[31] D. Li, M.B. Muller, S. Gilje, R.B. Kaner, G.G. Wallace, Processable aqueous dispersions of graphene nanosheets, Nat. Nanotechnol. 3 (2008) 101 105, https://doi.org/10.1038/nnano.2007.451.

[32] I.K. Moon, J. Lee, R.S. Ruoff, H. Lee, Reduced graphene oxide by chemical graphitization, Nat. Commun. 1 (2010) 73, https://doi.org/10.1038/ ncomms 1067.

[33] J. Jagiello, J.P. Olivier, 2D-NLDFT adsorption models for carbon slit-shaped pores with surface energetical heterogeneity and geometrical corrugation, Carbon 55 (2013) 70 80, https://doi.org/10.1016/j.carbon.2012.12.011.

[34] G. Srinivas, J.W. Burress, J. Ford, T. Yildirim, Porous graphene oxide frameworks: synthesis and gas sorption properties, J. Mater. Chem. 21 (2011) 11323 11329, https://doi.org/10.1039/C1JM11699A.

[35] J.W. Burress, S. Gadipelli, J. Ford, J.M. Simmons, W. Zhou, T. Yildirim, Graphene oxide framework materials: theoretical predictions and experimental results, Angew. Chem. Int. Ed. 49 (2010) 8902 8904, https://doi.org/10.1002/ anie. 201003328.

[36] C. Portet, P.L. Taberna, P. Simon, C. Laberty-Robert, Modification of Al current collector surface by sol gel deposit for carbon carbon supercapacitor applications, Electrochim. Acta 49 (2004) 905 912, https://doi.org/10.1016/ j.electacta.2003.09.043.

[37] R. de Levie, On porous electrodes in electrolyte solutions: I. Capacitance effects, Electrochim. Acta 8 (1963) 751 780, https://doi.org/10.1016/00134686(63)80042-0.

[38] R. de Levie, On porous electrodes in electrolyte solutions IV, Electrochim. Acta 9 (1964) 1231 1245, https://doi.org/10.1016/0013-4686(64)85015-5.

[39] J. Segalini, B. Daffos, P.L. Taberna, Y. Gogotsi, P. Simon, Qualitative electrochemical impedance spectroscopy study of ion transport into sub-nanometer carbon pores in electrochemical double layer capacitor electrodes, Electrochim. Acta 55 (2010) 7489 7494, https://doi.org/10.1016/ j.electacta.2010.01.003.

[40] F. Bardé, P.L. Taberna, J.M. Tarascon, M.R. Palacín, Evidence for electronic and ionic limitations at the origin of the second voltage plateau in nickel electrodes, as deduced from impedance spectroscopy measurements, J. Power Sources $179 \quad(2008) \quad 830836, \quad$ https://doi.org/10.1016/ j.jpowsour.2008.01.045.

[41] J.M. Griffin, A.C. Forse, W.-Y. Tsai, P.-L. Taberna, P. Simon, C.P. Grey, In situ NMR and electrochemical quartz crystal microbalance techniques reveal the structure of the electrical double layer in supercapacitors, Nat. Mater. 14 (2015) 812, https://doi.org/10.1038/nmat4318.

[42] D. Aurbach, M.D. Levi, G. Salitra, N. Levy, E. Pollak, J. Muthu, Cation trapping in highly porous carbon electrodes for EDLC cells, J. Electrochem. Soc. 155 (2008) A745 A753, https://doi.org/10.1149/1.2957911.

[43] R. Lin, P. Huang, J. Ségalini, C. Largeot, P.L. Taberna, J. Chmiola, Y. Gogotsi, P. Simon, Solvent effect on the ion adsorption from ionic liquid electrolyte into sub-nanometer carbon pores, Electrochim. Acta 54 (2009) 70257032 , https://doi.org/10.1016/j.electacta.2009.07.015.

[44] P.L. Taberna, P. Simon, J.F. Fauvarque, Electrochemical characteristics and impedance spectroscopy studies of carbon-carbon supercapacitors, J. Electrochem. Soc. 150 (2003) A292 A300, https://doi.org/10.1149/ 
1.1543948.

[45] K.S. Cole, R.H. Cole, Dispersion and absorption in dielectrics I. Alternating current characteristics, J. Chem. Phys. 9 (1941) 341 351, https://doi.org/ 10.1063/1.1750906.

[46] B. Abdulhakeem, B. Farshad, M. Damilola, T. Fatemeh, F. Mopeli, D. Julien, M. Ncholu, Morphological characterization and impedance spectroscopy study of porous 3D carbons based on graphene foam-PVA/phenolformaldehyde resin composite as an electrode material for supercapacitors, RSC Adv. 4 (2014) 39066 39072, https://doi.org/10.1039/C4RA05425C.
[47] D. Qu, H. Shi, Studies of activated carbons used in double-layer capacitors, J. Power Sources 74 (1998) 99 107, https://doi.org/10.1016/S0378-7753(98) 00038-X.

[48] R.B. Moghaddam, P.G. Pickup, Electrochemical impedance study of the polymerization of pyrrole on high surface area carbon electrodes, Phys. Chem. Chem. Phys. 12 (2010) 4733 4741, https://doi.org/10.1039/B925381E.

[49] H.-K. Song, Y.-H. Jung, K.-H. Lee, L.H. Dao, Electrochemical impedance spectroscopy of porous electrodes: the effect of pore size distribution, Electrochim. Acta 44 (1999) 3513 3519, https://doi.org/10.1016/S0013-4686(99)00121-8. 